\title{
Correlation between prescribing quality and pharmaceutical costs in English primary care:
}

\author{
national cross-sectional analysis
}

\begin{abstract}
Background

Both pharmaceutical costs and qualityindicator performance vary substantially between general practices, but little is known about the relationship between prescribing costs and quality.

\section{Aim}

To measure the association between prescribing quality and pharmaceutical costs among English general practices.
\end{abstract}

\section{Design and setting}

Cross-sectional observational study using data from the Quality and Outcomes Framework and the Prescribing Analysis and Cost database from all 8409 general practices in England in 2005-2006

\section{Method}

Correlation between practice achievement of 26 prescribing quality indicators in eight prescribing areas and related pharmaceutical costs was examined.

\section{Results}

There was no significant association between the overall achievement of quality indicators and related pharmaceutical costs $(P=0.399)$. Mean achievement of quality indicators across all eight prescribing areas was $79.0 \%$ (standard deviation $4.4 \%)$. There were small positive correlations in five prescribing areas: influenza vaccination, beta blockers, angiotensin converting enzyme inhibitors, lipid lowering, and antiplatelet treatment (all $P<0.001$ ). There were small negative correlations in two prescribing areas: hypertension $(P<0.001)$ and smoking cessation $(P=0.018)$.

\section{Conclusion}

Correlations between prescribing quality and pharmaceutical costs were much smaller than expected; possible explanations for this include a substantial variation in rates of prescribing outside evidence-based protocols, and use of expensive pharmaceuticals instead of cheaper effective alternatives. There remains considerable scope for some practices to make pharmaceutical cost savings while improving quality performance. The ratio of quality scores to related pharmaceutical costs could be developed into a performance indicator.

\section{Keywords}

cost effectiveness; economics, pharmaceutical primary health care; quality indicators; quality of health care.

\section{INTRODUCTION}

Cost-effectiveness is an important dimension of appropriate prescribing. ${ }^{1-4}$ General practices are under increasing pressure to control prescribing costs while continuing to improve health outcomes; put simply, this means prescribing drugs when there is good evidence to indicate that they will improve health and avoiding them if evidence for significant benefit is lacking. Evidence from a number of studies in England and the US has shown that prescribing can be 'cost ineffective', $6-10$ thereby indicating that some GPs find it difficult to know when to avoid prescribing.

There are currently no generally applicable methods for measuring the cost-effectiveness of prescribing and monitoring it against national benchmarks. Cost data are available, but low pharmaceutical cost alone is not a clear indicator of cost-effective prescribing, as it may be due to the under-treatment of highbenefit patients which can result in poor outcomes and high future care costs. Information on outcomes is harder to find, but process measures - which have been linked to improved outcomes - are routinely available. Indicators in the Quality and Outcomes Framework (QOF), a UK national pay-for-performance programme, are a good example; ${ }^{11}$ they are also useful because the pharmaceutical costs associated with prescribing to patients

R Fleetcroft, MSc, MD, FRCGP, MRCP, FHEA lecturer in general practice; $\mathbf{N}$ Steel, PhD, MRCGP, FFPH, clinical senior lecturer; $\mathbf{A}$ Howe, MA, MD, MEd, FAcadMed, FRCGP, professor of primary care, Primary Care Group, School of Medicine, Health Policy and Practice, University of East Anglia, Norwich. R Cookson, DPhil, senior lecturer, Department of Social Policy and Social Work, University of York, York.

Address for correspondence

Nicholas Steel, Population Health and Primary included in the QOF can be estimated reasonably accurately. There are 26 clinical indicators in the QOF (Appendix 1), all of which include a prescribing intervention that is clinically effective; 22 have evidence for mortality reduction (Appendix 2) and many have evidence for costeffectiveness. ${ }^{12,13}$

A large-scale national study was conducted to determine whether prescribing is cost-effective. Routine data, which are available in the NHS at generalpractice level, were used to develop a method for providing a simple and partial indication of the cost-effectiveness of prescribing by general practices. It was hypothesised that if all GPs prescribe in a cost-effective manner with regard to QOF indicators and other areas of prescribing, a higher achievement of QOF quality indicators will be associated with a higher related pharmaceutical spend.

\section{METHOD}

Data on quality of care from the QOF were combined with data on related pharmaceutical costs from the Prescribing Analysis and Cost (PACT) database. The practice-level relationship between quality-indicator performance and associated pharmaceutical costs was analysed and adjusted for practice-level variables that are known to be associated with need, across eight different

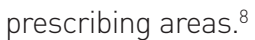

Care Department, Norwich Medical School University of East Anglia, Norwich Research Park, Norwich, NR4 7TJ.

E-mail: n.steelduea.ac.uk

Submitted: 6 December 2010; Editor's response: 13 January 2011; final acceptance: 4 April 2011. (CBritish Journal of General Practice This is the full-length article (published online 30 Aug 2011) of an abridged version published in print. Cite this article as: Br J Gen Pract 2011; DOI: 10.3399/bjgp11X593839. 


\section{How this fits in}

Previous research has identified substantial variation in both quality-indicator performance and prescribing costs in primary care practices, but the strength of the relationship between quality-indicator performance and associated prescribing costs is not known. This cross-sectional analysis of every GP practice in England with available data found individually small and collectively insignificant associations between quality performance and associated pharmaceutical costs in eight prescribing areas. Some practices could make considerable pharmaceutical cost savings while, at the same time, improving quality performance.

\section{Data collection}

The study group obtained data for all 26 indicators, which included a prescribing intervention in the QOF, for all 8409 practices in England for 2005-2006 (A Wagner, personal communication, 2006). These indicators were grouped into eight distinct prescribing areas:

- angiotensin converting enzyme (ACE) inhibitor and angiotensin receptor blocker (ARB) treatment;

- antiplatelet treatment;

- beta blockers;

- diabetes (control of blood sugar);

- hypertension;

- influenza vaccination;

- lipid lowering; and

- smoking cessation.

Pharmaceutical spend for each of the 26 prescribing interventions was obtained for every practice in England for 2005-2006 from the Prescription Pricing Division (Prescription Pricing Authority, unpublished data, 2007).

Other variables known to be associated with variation in pharmaceutical costs and quality performance at practice level were identified from a previous study in English primary care. ${ }^{8}$ These were: disease prevalence; number of GPs; proportion of female GPs and GP trainers; dispensing status; rural or urban location; deprivation status, as estimated by the low income score index; consultation length; and generic prescribing rates. These data were obtained from the National Primary Care Trusts Database (A Wagner, personal communication, 2006).

\section{Data analysis}

A dataset containing QOF prescribing qualityindicator performance, pharmaceutical costs, and practice and population characteristics for 2005-2006 was constructed for all 8409 practices in England. Practices for which data were not available and those with a list size of less than $1000 \quad(n=24)$ were excluded.

The unweighted mean score for all 26 QOF prescribing indicators was used to create an overall combined quality score $(0-100 \%)$, and a quality score was produced for each prescribing area. To compute the related prescribing costs, the pharmaceutical costs related to each prescribing area were divided by the number of patients on the disease registers in that area, creating a pharmaceutical cost per QOF patient for each prescribing area. An overall combined pharmaceutical cost per QOF patient was determined by adding together the pharmaceutical costs for all eight prescribing areas, and dividing this number by the total number of patients on the disease registers in the QOF for those areas.

The relationships between the quality scores and associated pharmaceutical costs were analysed using both simple bivariate correlation and multiple regression analysis, along with other possible explanatory variables in SPSS (version 16). Pearson's correlation coefficient and linear regression were used, as both quality performance and pharmaceutical costs were normally distributed.

\section{Sensitivity analysis}

Simply adding together or averaging out individual quality scores has been criticised as it assumes that all interventions are equally effective and carry the same weighting in combination. ${ }^{14}$ This problem was addressed in sensitivity analysis by weighting each QOF prescribing indicator by its potential to save lives, using data from a previous study on the health gain potential of the QOF.13 This allowed the combination of the different indicators into a single summary indicator, using weights based on health gain.

\section{RESULTS}

The mean quality score across all prescribing areas was $79.0 \%$ (standard deviation [SD] 4.4\%; Table 1), and the mean pharmaceutical spend per QOF patient E149.79 (SD E35.32; Table 2). The statistical dispersion of the prescribing costs was four times greater compared with the qualityindicator scores /coefficient of variation of combined quality score $=0.06 \%$, and of 
combined pharmaceutical costs $=0.24 \%$ ).

Table 3 details the associations between the achievement of prescribing quality indicators and pharmaceutical costs. There was no association between overall prescribing quality-indicator achievement and associated pharmaceutical costs (Pearson's $r-0.012, P=0.399$, multiple regression beta coefficient on cost $0.003, P$ = 0.093); the sensitivity analysis gave similar non-significant results with overall quality score weighted by health gain as the dependent variable (Pearson's $r-0.022, P=$ 0.110 and multiple regression beta coefficient on cost $-0.008, P=0.788$ ). There were small statistically significant associations in individual prescribing areas, although these were not consistent.

Positive associations between prescribing quality-indicator achievement and associated pharmaceutical spend existed in five areas: ACE/ARB treatment (Pearson's $r$ 0.141, $P<0.001$ ); antiplatelet treatment (Pearson's $r 0.058, P<0.001$ ); beta blockers (Pearson's $r$ 0.149, $P<0.001$ ); influenza vaccination (Pearson's $r$ 0.167, $P<0.001$ ); and lipid lowering (Pearson's $r$ 0.092, $P<0.001)$. There were negative associations in two areas: hypertension (Pearson's $r-0.058, P<0.001$ ) and smoking cessation (Pearson's $r-0.027, P=0.018$ ). These associations are small: for example with beta blockers, the square of the Pearson's $r$ of $0.149=0.022$, suggesting that variation in prescribing cost explains only $2.2 \%$ of the QOF score variation. An increase in pharmaceutical spend of $€ 1$ per patient on beta blockers ljust over $2 \%$ of the mean spend of $€ 52.86$ on beta blockers per patient) is associated with an increase in the quality indicator of just 0.047 of one percentage point.

There was a consistent positive association between prescribing qualityindicator achievement and higher rates of generic prescribing. Higher prescribing quality-indicator achievement was also associated with being a dispensing practice in all eight prescribing areas. Increasing deprivation scores represented by the low income score index were associated with falling quality scores in five clinical areas (available from the authors).

Scatter plots (available from the authors) displayed some unusual patterns in three clinical areas. In ACE/ARB treatment and

\begin{tabular}{|c|c|c|c|c|}
\hline Prescribing area & $\begin{array}{c}\text { General } \\
\text { practices, } n\end{array}$ & $\begin{array}{c}\text { Mean quality } \\
\text { indicator score, \% }\end{array}$ & $\begin{array}{l}\text { Standard } \\
\text { deviation }\end{array}$ & $\begin{array}{l}\text { Coefficient of } \\
\text { variation, \% }\end{array}$ \\
\hline ACE/ARB & 7618 & 82.05 & 8.62 & 0.11 \\
\hline Antiplatelet therapy & 7975 & 89.75 & 5.62 & 0.06 \\
\hline Beta blockers & 7997 & 50.94 & 8.16 & 0.16 \\
\hline Diabetes & 8154 & 76.43 & 7.67 & 0.10 \\
\hline Hypertension & 7996 & 74.83 & 7.82 & 0.10 \\
\hline Influenza vaccination & 7982 & 79.26 & 6.83 & 0.09 \\
\hline Lipid lowering & 7997 & 70.00 & 9.51 & 0.14 \\
\hline Smoking cessation & 7817 & 92.08 & 5.78 & 0.06 \\
\hline Combined score & 7491 & 79.01 & 4.41 & 0.06 \\
\hline
\end{tabular}

Table 2. Prescribing cost in eight prescribing areas

\begin{tabular}{lcccc} 
Prescribing area & $\begin{array}{c}\text { General } \\
\text { practices, } \boldsymbol{n}\end{array}$ & $\begin{array}{c}\text { Pharmaceutical } \\
\text { spend per } \\
\text { QOF patient, } \mathbf{E}\end{array}$ & $\begin{array}{c}\text { Standard } \\
\text { deviation, } \mathbf{\in}\end{array}$ & $\begin{array}{c}\text { Coefficient of } \\
\text { variation, } \%\end{array}$ \\
\hline ACE/ARB & 7978 & 855.35 & 587.89 & 0.69 \\
\hline Antiplatelet therapy & 7833 & 79.07 & 31.38 & 0.40 \\
\hline Beta blockers & 7985 & 52.86 & 28.04 & 0.53 \\
\hline Diabetes & 7986 & 195.29 & 47.36 & 0.24 \\
\hline Hypertension & 5417 & 87.23 & 17.99 & 0.21 \\
\hline Influenza vaccination & 7982 & 29.94 & 21.46 & 0.72 \\
\hline Lipid lowering & 7985 & 345.12 & 158.00 & 0.46 \\
\hline Smoking cessation & 7981 & 21.56 & 13.31 & 0.62 \\
\hline Combined cost per QOF patient & 5473 & 149.79 & 35.32 & 0.24 \\
\hline ACE $=$ angiotensin converting enzyme. ARB = angiotensin receptor blocker. QOF = Quality and Outcomes \\
Framework.
\end{tabular}




\begin{tabular}{|c|c|c|c|c|}
\hline \multirow{2}{*}{$\begin{array}{l}\text { Prescribing area } \\
\text { ACE/ARB }\end{array}$} & \multicolumn{2}{|c|}{$\begin{array}{l}\text { Correlation } \\
\text { (multiple regression) }\end{array}$} & \multicolumn{2}{|c|}{$\begin{array}{c}\text { Correlation } \\
\text { (bivariate) }\end{array}$} \\
\hline & $\mathrm{R}^{2}$ & 0.033 & Pearson's $r$ & 0.141 \\
\hline & Beta & 0.003 & $P$-value & $<0.001$ \\
\hline & $P$-value & $<0.001$ & $n$ & 7600 \\
\hline \multirow[t]{3}{*}{ Antiplatelet treatment } & $\mathrm{R}^{2}$ & 0.020 & Pearson's $r$ & 0.058 \\
\hline & Beta & 0.014 & $P$-value & $<0.001$ \\
\hline & $P$-value & $<0.001$ & $n$ & 7811 \\
\hline \multirow[t]{3}{*}{ Beta blockers } & $\mathrm{R}^{2}$ & 0.042 & Pearson's $r$ & 0.149 \\
\hline & Beta & 0.047 & $P$-value & $<0.001$ \\
\hline & $P$-value & $<0.001$ & $n$ & 7962 \\
\hline \multirow[t]{3}{*}{ Diabetes } & $\mathrm{R}^{2}$ & 0.098 & Pearson's $r$ & 0.000 \\
\hline & Beta & 0.005 & $P$-value & 0.998 \\
\hline & $P$-value & 0.007 & $n$ & 7960 \\
\hline \multirow[t]{3}{*}{ Hypertension } & $\mathrm{R}^{2}$ & 0.044 & Pearson's $r$ & -0.058 \\
\hline & Beta & -0.021 & $P$-value & $<0.001$ \\
\hline & $P$-value & $<0.001$ & $n$ & 5415 \\
\hline \multirow{3}{*}{ Influenza vaccination } & $\mathrm{R}^{2}$ & 0.108 & Pearson's $r$ & 0.167 \\
\hline & Beta & 0.001 & $P$-value & $<0.001$ \\
\hline & $P$-value & $<0.001$ & $n$ & 7946 \\
\hline \multirow[t]{3}{*}{ Lipid lowering } & $\mathrm{R}^{2}$ & 0.076 & Pearson's $r$ & 0.092 \\
\hline & Beta & 0.009 & $P$-value & $<0.001$ \\
\hline & $P$-value & $<0.001$ & $n$ & 7962 \\
\hline \multirow[t]{3}{*}{ Smoking cessation } & $R^{2}$ & 0.027 & Pearson's $r$ & -0.027 \\
\hline & Beta & -0.012 & $P$-value & 0.018 \\
\hline & $P$-value & 0.018 & $n$ & 7790 \\
\hline \multirow[t]{3}{*}{ Combined score, equal weights } & $\mathrm{R}^{2}$ & 0.080 & Pearson's $r$ & -0.012 \\
\hline & Beta & 0.003 & $P$-value & 0.399 \\
\hline & $P$-value & 0.093 & $n$ & 5176 \\
\hline \multirow{3}{*}{$\begin{array}{l}\text { Sensitivity analysis, combined } \\
\text { score with health gain weights }\end{array}$} & $\mathrm{R}^{2}$ & 0.061 & Pearson's $r$ & -0.022 \\
\hline & Beta & -0.008 & $P$-value & 0.110 \\
\hline & $P$-value & 0.788 & $n$ & 7497 \\
\hline
\end{tabular}

${ }^{a}$ Beta $=$ non standardised beta coefficient on cost; coefficients on other covariates are available from the authors. $A C E=$ angiotensin converting enzyme. $A R B=$ angiotensin receptor blocker.

antiplatelet therapy, some practices reported $100 \%$ performance. As it is unlikely that all patients would be both eligible and receive treatment, this finding may reflect an error in the data at the practice level. In smoking cessation, several practices achieved high quality performance without incurring significant prescribing costs. This area is, however, unique for two reasons: smoking cessation services were delivered by some primary care trusts in the community with no additional cost to the practice, and achievement of this indicator involves giving advice on smoking cessation and does not necessitate prescribing smoking cessation drugs. Advice-giving could reach almost $100 \%$ of the practice population that smokes.

\section{DISCUSSION}

\section{Summary}

There was no statistically significant relationship between the combined prescribing costs for each general practice in England and their achievement of the combined quality indicator. Within individual prescribing areas there were some small associations between cost and quality; these were positive in five areas (ACE/ARB, antiplatelet treatment, beta blockers, influenza vaccination, and lipid lowering), and negative in two areas (hypertension and smoking cessation).

\section{Strengths and limitations}

The strength is that this study uses data on performance and prescribing, and combines them to perform a systematic analysis of costs and quality. The data were adjusted for patients who had been excluded on the basis of not being suitable for the intervention (by the process of exception reporting by general practices).

There are a number of limitations. The study only provides a partial indication of the cost-effectiveness of prescribing because 
routine data were not available on the health outcomes of care or the nonpharmaceutical costs related to prescribing, such as GP and nurse time. In addition, the PACT data used does not indicate whether prescribing was appropriate, as these data are aggregated at the practice level and not linked to the patient record

It was not possible to determine how much of the variation in pharmaceutical costs was due to the choice of expensive drugs over cheaper alternatives.

The study did not examine organisational constraints and incentives on GPs prescribing behaviour and there may be other unknown variables not included in the analysis that could explain some of the variation in practice.

Although the QOF clinical indicators are only cost-effective in certain circumstances, this study did not measure the amount of prescribing outside of those. The prescribing that fell within scope of the QOF was measured in the current study, but other studies have shown that such prescribing is only cost-effective in certain circumstances. As an example: clopidogrel was not cost-effective when compared with aspirin in patients with myocardial infarction; ${ }^{15}$ aspirin may have no place in primary prevention;16 guidance from the National Institute for Health and Clinical Excellence does not recommend beta blockers for anxiety because of evidence for lack of efficacy $;^{17}$ the British National Formulary does not recommend clonidine for migraine because of its side-effect profile; ${ }^{18}$ influenza vaccination is not costeffective in patients who are healthy; ${ }^{19}$ and statins are only cost-effective in primary prevention when used for high-risk patients ${ }^{20}$ and those who are low risk may get no benefit at all. ${ }^{21}$

Assuming that there is an appropriate rate of prescribing of QOF drugs outside of QOF indications by each practice, this should not alter the slope of the cost-quality relationship. These limitations do not alter the conclusion that there is considerable scope for practices to make pharmaceutical savings while improving performance.

\section{Comparison with existing literature}

These results update and extend to a national sample the previously reported lack of association between the quality and costs of prescribing in one region of England. ${ }^{8}$ They complement the previous finding that the widely differing prescribing rates in general practices in England were not explained by healthcare need.? This study found that higher generic prescribing was associated with higher-quality performance, despite earlier findings that generic prescribing was primarily aimed at cost minimisation rather than quality performance. 22 The relationship between increasing deprivation lusing the low income score index as the proxyl and decreasing quality-indicator performance is similar to findings from a study of general practices in Scotland. ${ }^{23}$ The reported high achievement of indicators (79\%) is similar to the achievement reported in a national study of 8688 people in England using different methods $174.6 \%$ achievement of QOF conditions). ${ }^{24}$

\section{Implications for research and practice}

If GP prescribing were uniformly costeffective, a substantial positive association between cost and quality would be expected. For example, if prescribing statins is limited to patients at high risk according to QOF indicator definitions, using a costeffective statin such as simvastatin would cost $€ 46.41$ per patient in 1 year. Other things being equal, an increase in prescribing costs of $€ 1$ per QOF patient would be associated with an increase of 2.15 percentage points in quality-indicator performance. However, the beta coefficient in the current study is 0.009 , indicating that an increase in prescribing cost of statins of $€ 1$ per QOF patient is associated with an increase of only 0.009 of a percentage point in quality-indicator performance; that is, 278 times smaller than expected. As such, the observed cost-quality associations in five of the individual prescribing areas are much smaller than would be expected if prescribing were uniformly cost-effective.

This is, therefore, fairly clear evidence that prescribing is not uniformly costeffective, and that some GP practices are able to achieve higher prescribing quality scores than others, while keeping their prescribing costs substantially lower. This study's data do not allow us to pinpoint the reasons for the lack of any strong positive association between prescribing qualityindicator achievement and associated pharmaceutical costs, but there are two broad possibilities. GPs may vary considerably in their use of more expensive drugs compared with less expensive drugs; the Audit Commission has estimated that the use of more expensive drugs over cheaper alternatives cost an additional £200 million in England in 2006. ${ }^{25}$ In addition, there may also be a wide variation in their prescribing of QOF-indicated drugs to patients outside QOF areas of care. 
Prescribing is not cost-effective if a practice has a low rate of prescribing recommended drugs to high-benefit patients included in QOF domains, but has high rates of prescribing these drugs to patients outside QOF domains where such drugs are not supported by a strong evidence base.

There could be substantial savings in drug expenditure if GPs use QOF-indicated drugs appropriately, and use cheaper drugs when available. At present, the QOF incentivises high performance in indicators but does not explicitly incentivise costeffective prescribing. ${ }^{11}$ As no relationship between the cost and quality of prescribing was found, theoretically, all practices should be able to prescribe at low cost with high quality. Practices performing at low quality and high cost could be targeted first for change as these comprise the areas where maximum quality and cost gains could be realised.

This study's approach to assessing quality performance as a ratio of the quality scores to related pharmaceutical costs could be developed into a performance indicator that includes aspects of both quality performance and prescribing costs. If further research supports the findings of this study, incentives could be used through GP consortia to reduce pharmaceutical costs while maintaining and improving quality. Unanswered questions and areas for future research include examining the patient record to establish how much of the variation in prescribing costs is due to inappropriate prescribing and how much is due to the use of more expensive drugs over cheaper alternatives.

The association between prescribing quality indicators and pharmaceutical costs may have increased since 2005-2006, but the continued operation of the QOF means a dramatic change is unlikely. This is because the QOF focuses on reducing inappropriate variation in high-benefit prescribing, which drives the quality side of the equation but does not address the inappropriate variation in low-benefit/high-cost prescribing that drives the cost element. The slowdown in NHS spending from 2010-2011 may put pressure on practices to reduce pharmaceutical costs, so we may see a stronger association emerge in the next few years. 


\section{REFERENCES}

1. Department of Health. A first class service: quality in the new NHS. London: $\mathrm{DOH}, 1998$.

http://www.dh.gov.uk/en/Publicationsandstatistics/Publications/PublicationsP olicyAndGuidance/DH_4006902 (accessed 21 Jul 2011).

2. Chapman S, Durieux P, Walley T. Good prescribing practice. In Mossialos E, Mrazek M, Walley T (eds). Regulating pharmaceuticals in Europe: striving for efficiency, equity and quality. Maidenhead: Open University Press, 2004.

3. Audit Commission. A prescription for improvement: towards more rational prescribing in general practice. London: HMSO, 1994.

4. NHS Executive. NHS performance indicators. London: Department of Health, 2000.

http://www.performance.doh.gov.uk/nhsperformanceindicators/hlpi2000/h1 117s.html (accessed 21 Jul 2011)

5. Department of Health. Equity and excellence: liberating the NHS. London: $\mathrm{DOH}, 2010$

http://www.dh.gov.uk/en/Publicationsandstatistics/Publications/PublicationsP olicyAndGuidance/DH_117353 (accessed 21 Jul 2011).

6. National Prescribing Centre and the National Primary Care Research and Development Centre. Modernising Medicines Management. A guide to achieving benefits for patients, professionals and the NHS (book 2). Liverpool: NPC, 2002. http://www.pdptoolkit.co.uk/files/ppa/mmm_guide_2.pdf laccessed 10 Aug 2011).

7. Ward P, Noyce P, St Leger AS. Are GP practice prescribing rates for coronary heart disease drugs equitable? A cross sectional analysis in four primary care trusts in England. J Epidemiol Community Health 2004; 58(2): 89-96.

8. Fleetcroft $\mathrm{R}$, Cookson $\mathrm{R}$. The relationship between prescribing expenditure and quality in primary care: an observational study. $\mathrm{Br} J$ Gen Pract 2006; 56(529): 613-619.

9. McGlynn ES, Asch J, Adams J, et al. The quality of health care delivered to adults in the USA. N Engl J Med 2003; 348(26): 2635-2645

10. Fisher E, Wennberg DE, Stukel TA, et al. The implications of regional variations in Medicare Spending Part 2: health outcomes and satisfaction with care. Ann Intern Med 2003; 138(4): 297.

11. NHS Confederation. New General Medical Services Contract 2003. Investing in general practice. London: NHS Confederation, 2003.

12. Walker S, Mason A, Claxton $\mathrm{K}$, et al. Value for money and the quality and outcomes framework in primary care in the NHS. Br J Gen Pract 2010; 60(574): 352-357.
13. Fleetcroft R, Parekh-Bhurke S, Howe AC, et al. The pay-for-performance programme in primary care: estimation of population mortality reduction in England. Br J Gen Pract 2010; 60(578): 649-654.

14. Guthrie B. Measuring the quality of healthcare systems using composites. BMJ 2008; 337: a639.

15. Schleinitz MD, Weiss JP, Owens DK. Clopidogrel versus aspirin for secondary prophylaxis of vascular events: a cost-effectiveness analysis. Am J Med 2004; 116(12): 797-806.

16. Antithrombotic Trialists' (ATT) Collaboration. Aspirin in the primary and secondary prevention of vascular disease: collaborative meta-analysis of individual participant data from randomised trials. Lancet 2009; 373(9678): 1849-1860.

17. National Institute for Health and Clinical Excellence. Anxiety: management of anxiety (panic disorder, with or without agoraphobia, and generalised anxiety disorder) in adults in primary, secondary and community care. CG22. 2004 http://guidance.nice.org.uk/CG22 (accessed 10 Aug 2011).

18. British National Formulary. BNF 51. London: British Medical Association and Royal Pharmaceutical Society of Great Britain, 2006

19. Allsup S, Haycox A, Regan M, Gosney M. Is influenza vaccination cost effective for healthy people between ages 65 and 74 years? A randomised controlled trial. Vaccine 2004; 23(5): 639-645.

20. National Institute for Health and Clinical Excellence. NICE Technology Appraisal No 94: Statins for the prevention of cardiovascular events. London: NICE, 2006. http://www.nice.org.uk/nicemedia/pdf/TA094guidance.pdf laccessed 21 Jul 2011).

21. Ray K, Seshasai, Sever $P$, et al. Statins and all-cause mortality in high-risk primary prevention. Arch Intern Med 2010; 170(12): 1024-1031.

22. Campbell SM, Cantrill JA, Roberts D. Prescribing indicators for UK general practice: Delphi consultation study. BMJ 2000; 321(7258): 425-428.

23. McLean G, Sutton M, Guthrie B. Deprivation and quality of primary care services: evidence for persistence of the inverse care law from the UK Quality and Outcomes Framework. J Epidemiol Community Health 2006; 60(11): 917-922.

24. Steel N, Bachmann MO, Maisey S, et al. Self-reported receipt of care consistent with 32 quality indicators: a national population survey of adults over 50 years old in England. BMJ 2008; 337: a957.

25. Audit commission 2007. Prescribing costs in primary care. National Audit office.

http://www.nao.org.uk/publications/0607/prescribing_costs_in_primary_c.aspx laccessed 21 Jul 2011). 


\section{Appendix 1. Full descriptions of Quality and Outcomes Framework indicators}

Indicator Full description of clinical indicator

Asthma 5 The percentage of patients with asthma who smoke, and whose notes contain a record that smoking cessation advice or referral to a specialist service, if available, has been offered within the last 15 months

Asthma 7 The percentage of patients aged 16 or over with asthma who have had influenza immunisation in the preceding 1 September to 31 March

BP 3 The percentage of patients with hypertension who smoke, whose notes contain a record that smoking cessation advice or referral to a specialist service, if available, has been offered at least once

BP 5 The percentage of patients with hypertension in whom the last blood pressure (measured in the last 9 months) is 150/90 or less

CHD 4 The percentage of patients with coronary heart disease who smoke, whose notes contain a record that smoking cessation advice or referral to a specialist service, where available, has been offered within the last 15 months

CHD 6 The percentage of patients with coronary heart disease in whom the last blood pressure reading (measured in the last 15 months) is 150/90 or less

CHD 8 The percentage of patients with coronary heart disease whose last measured total cholesterol (measured in last 15 months) is $5 \mathrm{mmol} / \mathrm{l}$ or less

CHD 9 The percentage of patients with coronary heart disease with a record in the last 15 months that aspirin, an alternative anti-platelet therapy, or an anti-coagulant is being taken (unless a contraindication or side-effects are recorded)

CHD 10 The percentage of patients with coronary heart disease who are currently treated with a beta blocker (unless a contraindication or side-effects are recorded)

CHD 11 The percentage of patients with a history of myocardial infarction (diagnosed after 1 April 2003) who are currently treated with an ACE inhibitor

CHD 12 The percentage of patients with coronary heart disease who have a record of influenza immunisation in the preceding 1 September to 31 March

COPD 5 The percentage of patients with COPD who smoke, whose notes contain a record that smoking cessation advice or referral to a specialist service, if available, has been offered in the past 15 months

COPD 8 The percentage of patients with COPD who have had influenza immunisation in the preceding 1 September to 31 March

DM 4 The percentage of patients with diabetes who smoke and whose notes contain a record that smoking cessation advice or referral to a specialist service, where available, has been offered in the last 15 months

DM 6 The percentage of patients with diabetes in whom the last $\mathrm{HbA1C}$ is 7.4 or less lor equivalent test/reference range depending on local laboratoryl in last 15 months

DM 7 The percentage of patients with diabetes in whom the last $\mathrm{HbA1C}$ is 10 or less lor equivalent test/reference range depending on local laboratory) in last 15 months

DM 12 The percentage of patients with diabetes in whom the last blood pressure is 145/85 or less

DM 15 The percentage of patients with diabetes with proteinuria or micro-albuminuria who are treated with ACE inhibitors (or A2 antagonists)

DM17 The percentage of patients with diabetes whose last measured total cholesterol within the previous 15 months is 5 or less

DM 18 The percentage of patients with diabetes who have had influenza immunisation in the preceding 1 September to 31 March

LVD 3 The percentage of patients with a diagnosis of $\mathrm{CHD}$ and left ventricular dysfunction who are currently treated with ACE inhibitors (or A2 antagonists)

Stroke4 The percentage of patients with a history of TIA or stroke who smoke and whose notes contain a record that smoking cessation advice or referral to a specialist service, if available, has been offered in the last 15 months

Stroke 6 The percentage of patients with a history of TIA or stroke in whom the last blood pressure reading (measured in last 15 months) is 150/90 or less

Stroke 8 The percentage of patients with TIA or stroke whose last measured total cholesterol (measured in last 15 months) is $5 \mathrm{mmol} / \mathrm{l}$ or less

Stroke 9 The percentage of patients with a stroke shown to be non haemorrhagic, or a history of TIA, who have a record that aspirin, an alternative anti-platelet therapy, or an anticoagulant is being taken (unless a contraindication or side-effects are recorded)

Stroke 10 The percentage of patients with TIA or stroke who have had influenza immunisation in the preceding 1 September to 31 March 


\section{Appendix 2. Allocation of Quality and Outcomes Framework (QOF) indicators to prescribing areas and related British National Formulary (BNF) chapters, potential lives saved for each QOF indicator, and therapeutic indications for QOF drugs outside QOF}

\begin{tabular}{|c|c|c|c|c|}
\hline Prescribing area & QOF indicator ${ }^{\text {a11 }}$ & $\begin{array}{l}\text { Drugs } \\
\text { (BNF chapter) }{ }^{18}\end{array}$ & $\begin{array}{l}\text { Max lives saved per } \\
100000 \text { population }^{13}\end{array}$ & $\begin{array}{l}\text { Other therapeutic indications } \\
\text { for drugs outside QOF } \\
\text { indicator definitions (BNF indications) } \text { (18 }^{18}\end{array}$ \\
\hline \multirow[t]{3}{*}{ ACE/ARB } & CHD11 & ACE/ARB (2.5.5) & 1.5 & Heart failure \\
\hline & LVD3 & & 11.6 & \\
\hline & DM15 & & 3.4 & \\
\hline \multirow[t]{3}{*}{ Antiplatelet treatment } & CHD9 & Aspirin 75mg (2.9) & 24.8 & Prophylaxis of CHD \\
\hline & Stroke9 & Clopidogrel (2.9) & 15.8 & Peripheral vascular disease \\
\hline & & Dipyridamole (2.9) & & None \\
\hline \multirow[t]{6}{*}{ Beta blockers } & CHD10 & Beta blocker (2.4) & 45.9 & Arrhythmia \\
\hline & & & & Portal hypertension \\
\hline & & & & Thyrotoxicosis \\
\hline & & & & Heart failure \\
\hline & & & & Anxiety \\
\hline & & & & Phaechromocytoma \\
\hline \multirow[t]{2}{*}{ Diabetes } & DM6 & $\begin{array}{l}\text { Insulin/hypodermic (6.1.1) } \\
\text { equipment }\end{array}$ & 26.5 & None \\
\hline & DM7 & Oral antidiabetic agent (6.1.2) & 7.4 & \\
\hline \multirow[t]{8}{*}{ Hypertension } & CHD6 & Thiazide (2.2.1) & 11.3 & Oedema \\
\hline & BP5 & Beta blocker (2.4) & 48.2 & (listed above) \\
\hline & DM12 & Vasodilator (2.5.1) & 13.5 & Heart failure (hydralazine only) \\
\hline & Stroke6 & Centrally acting (2.5.2) & No data & Migraine (clonodine only) \\
\hline & & Alpha blocker (2.5.4) & & Benign prostatic hypertrophy \\
\hline & & ACE (2.5.5.1) & & (listed above) \\
\hline & & ARB (2.5.5.2) & & (listed above) \\
\hline & & Ca channel (2.6.2) & & None \\
\hline \multirow[t]{5}{*}{ Influenza vaccination } & CHD12 & Influenza vaccines (14.4) & 61.6 & Immunosupression \\
\hline & Stroke10 & & 28.1 & Front-line healthcare workers \\
\hline & DM18 & & 63.7 & \\
\hline & COPD8 & & 25 & \\
\hline & Asthma7 & & No data & \\
\hline \multirow[t]{3}{*}{ Lipid lowering treatment } & CHD8 & Lipid regulating drugs (2.12) & 15.8 & Primary hypercholesterolaemia \\
\hline & Stroke8 & & No data & \\
\hline & DM17 & & No data & \\
\hline \multirow[t]{6}{*}{ Smoking cessation treatment } & CHD4 & NRT & 2.4 & None \\
\hline & Stroke4 & Bupropion (both part of 4.10) & 1.1 & \\
\hline & BP3 & & 5.4 & \\
\hline & DM4 & & 2.4 & \\
\hline & COPD5 & & 2.6 & \\
\hline & Asthma5 & & 8.8 & \\
\hline
\end{tabular}

$\overline{A C E}=$ angiotensin converting enzyme. $A R B=$ angiotensin receptor blocker. 